\title{
THE ROLE OF THE FAMILY ECONOMY IN THEFT IN CHAHARMAHAL AND BAKHTIARI PROVINCE (CASE STUDY OF ADULT CRIMINALS IN PRISON)
}

\author{
M. Husseini ${ }^{1}$, V. Yaminpour ${ }^{2 *}$ \\ ${ }^{1}$ Department of Criminal law, E-campus, Islamic Azad University, Tehran, Iran \\ ${ }^{2}$ Member of faculty at East Tehran branch, Islamic Azad University, Tehran, Iran
}

Published online: 15 February 2017

\begin{abstract}
Security establishment without doubt is one of the main objectives in the management of any society in which crime creates instability and imposes costs to society, which is made up of families. Crime is a social phenomenon and its occurrence adversely affected by the different causes. So, given the sensitivity and its importance in the different societies in recent years, extensive studies have been done in order to identify and explain the causes of crime, particularly theft. It seems the most important causes of crime are economic factors that have a significant impact in the event of theft, because in most studies, statistically significant relationships between economic factors and the occurrence of this crime are confirmed. Thus, according to the sensitivity of the issue, it is also considered in recent years in our country and through it, the applied results have been obtained. This study, which was conducted on 108 prisoners committed to robbery, by the same token attempts to test the role of home economics in the crime of theft in Chaharmahal and Bakhtiari province by Pearson's correlation coefficient. The instrument used in this study was a questionnaire that examined variables such as addiction, unemployment, state administration, education, economic factors, etc. This study consisted of two hypotheses which are tested by Pearson correlation analysis $(+1,0,-1)$.
\end{abstract}

Keywords: theft, economic factors, Pearson, addiction, lack of skills.

\footnotetext{
Author Correspondence, e-mail: author@gmail.com doi: http://dx.doi.org/10.4314/jfas.v9i1s.691
} 


\section{INTRODUCTION}

Issues in relation to the family and its role in today's world people's actions are important issues which are the subjects of researches in economics, sociology, law, and so on fields and in the international instruments that have been investigated, too. Study of social deviations have been considered by social thinkers from long ago. A group of thinkers like Rousseau consider the human nature as an imprinting mirror and also the role of social education (Hatefi ARDAKANI, H., 2005). Crime is a multi-faceted phenomenon that had considered always by sociologists, lawyers, and economists. The main objectives of the criminology is to prevent crime and reform criminals. In the meantime the economic situation of a society is decisive for the actions of individuals. The sociologist J.Noteler believes, "The reasons for crimes committed by individuals should be studied within the community and based on social and cultural structures. And since the social and economic structures have a close relationship, it is expected that the economic structure to affect criminal acts (GHIASI Hafezi, Mohammed, 2003)." William Bungher in this regard says: "Economic factors, are the factor in all social structures and have significant impact on individual activities such as crime, especially if the economic factor be included the poverty, inequality, unemployment, inflation and economic opportunity costs. " According to Robert Merton's strain theory "If there is an unequal distribution of income in society, people who are economically in a lower positions, feel dissatisfied with their circumstances and hence, always kept under some sort of stress an there also is a possibility of violent behavior occurrence (Mohseni, Morteza, 1999)." In the meantime, Emile Dourcim considers the crime as a normal phenomenon an believes that, the crime has social functions, it doesn't mean we praise it, but in terms of its generality, we should consider it in all times and communities." Thus it can be concluded that crimes can be due to social factors (poverty, unemployment, family disruption, and income inequality) and the split in economy classes, and if people have the same terms of economic and other factors be modified, we will then be faced with reducing crime. Obviously, the adult today offenders are the yesterday's children and adolescents, who at critical junctures of their early life had extreme crisis and needed the support and attention of the family, educational institutions such as schools and education. Therefore, the importance of education and level of education can influence on crime and its development can reduce crime (Sadiq. Rahmatullah, 1997). The people who have been able to pass this crisis are the successful people in the current society and those who have gone astray inevitably, to a 
certain extent make up the current offender population. So, adolescence and youth in the development of personality is important and if it is not considered, we will be faced with a large number of delinquent and deviant adults and less hope there will be for the possibility to modify them (Hamed et al., 2010). In this study we investigate this issue that how the situation and domestic economic conditions of the perpetrators were have been convicted of theft? Some researchers believe that, economic crisis affects the family when the family is first in poverty and unemployment crisis and secondary crisis that is the economic crisis, exacerbated the situation. When the economic gap between different levels of society occurs, in this situation head of household or other adult family members are forced to provide the income to the family and turn to tedious and low income tasks. If these people do not have the ability to adapt to conditions occurred, in most cases turn to crime, which according to most of these people, theft is the easiest way to get rid of economic deadlock. Thus creating better jobs, led people to energy depletion and is of variables that could reduce crimes against property. Today, with advances in forensic science, researches that are done in this field include the investigation of crime and how people are guilty (Gould, Julius; Kolb, "If the expected utility William L., 1997). According to the theory of social benefits, Jeremy Bentham says "If a person's expected utility of crime is greater than the utility using time and other resources acquires, in these circumstances, he commits the crime." Without a doubt, poverty and financial needs have significant impact on burglary, because everyone have legal right to have the basic supplies, so basically, those who do not have financial needs, do steal less than others. Since the economic situation, poverty and deprivation are the causes of burglary, these factors lead to intense hatred of society and influence in the depths of the human soul and make them to commit robbery and other crimes. (Dehghan, 2009: 17). The importance of social and economic conditions in explaining the causes of theft is not a secret. Lacassagne on the impact of social environment says that "if it cannot be the sole factor, but it is the best and most important factor for theft and other crimes. His view can be summarized in the following formula:

- Every community has only its own criminals.

Poverty and material deprivation are perhaps the most important causative agents of theft. A person who is experiencing social damages, on one side, is psychologically humiliated and deceived and on the other hand, since he considers the society as the responsible for his exclusion and poverty, a sense of retaliation is to be nurtured in him. In this way, his efforts for 
poverty reduction may be illegal or in anti-social tracts and, be drawn to theft or crime. For example, in recent years due to inflation and the gap between the costs and revenues, the rate of theft has been increasing in our society. Most of these thieves are from poverty and little income class (Sotoudeh, 2002: 32). Given that, the de facto capital of each country are considered adults, thus providing education services for adult offenders, recognizing the economic and social situation of the whole people are important things that it is necessary that families, social workers and police to consider them in detailed planning for reconstruction and restoration of their personality in order to minimize and avoid committing crimes again. In the meantime, attention to the whole range of offender and the possibility of their re-admission within the family (after leaving the prison), as well as meeting their emotional needs, can be an effective step to combat crime in this area. On the other hand adequate protection from the authorities to enter the parties into a healthy labor market and create jobs for these people seems necessary and somehow is the way of prevention of employment to false jobs.

Thus, according to economic conditions and large fluctuations in economic variables of Chaharmahal and Bakhtiari Province, it seems that it should become clear that how variables such as unemployment, inflation, Inequality of income distribution, and GDP are related to the crime in the region. And economic policy makers should also consider the social consequences resulting from an economic aim and change in crime rates and economic impacts. In this study, we seek to explore the relationship between economic variables and their impact on crimes, to suggest that to the economic and legal decision-making institutions of the province, and to form a joint working group to explain the relationship between these variables, and finally become able, once before the crime, to find solutions to prevent crime and thereby, society and families incur fewer costs.

Stealing History:

Robbery is one of the oldest crimes against property that perhaps from the very beginning of the concept of property in human societies has been committed, and usually severe penalties for the perpetrators in religions, tribes and communities have been anticipated for it. In the assembly of the Laws of Hammurabi, the oldest codified law, the punishment for this act in article 22, was anticipated as killing. This crime because of its easier benefits (in comparison with crimes such as fraud) and evident benefits from it (compared to crimes against persons) makes up a large proportion of crimes committed in different countries, and the same frequency requires special 
attention (Mir Mohammad Sadeghi, 2014: 245). Theft can be seen in different ways in different societies. This phenomenon has changed over time. But the only thing that has remained constant since its formation, is its ugly and condemned nature. Over time, practices and procedures of theft, property type and stolen objects and means used to commit robbery has been changed, so that today some thieves use the latest techniques and technology to advance their work. As a result, the coping strategies and ways to deal with it in accordance with the transformation of theft have changed. In other words, because in our times the means of theft are altered, it has become more difficult to deal with (Sotoudeh, 2007: 150).

Wealth effect on crime:

In order to prevent the impression that the poverty eradication eliminates any crime from the community, we are to talk about the economic impact of the spread of wealth on crime. There is no doubt that the increase in wealth can also occur as a factor causing offense. As has been observed many people are living with poverty and at the same time with dignity and nobility, and not only do not act crime, but also regard that as a means of perfection and glory and their happiness. Contrary, many people without the need and also with the enjoyment of great wealth, are doing theft, fraud, breach of trust and other misdemeanors. Most of misappropriations and big tricks and massive smugglings are of the kinds. Statistics show that even in times of economic progress, sometimes crime was on the rise, as Raffaele Garofalo, the famous scientist and criminologist, has noted that in France, at a time when wages had gone up $45 \%$ and the country was in a period of economic expansion, the crime rates had increased from 100 to 245 . The statistics released by the Ministry of Justice of Iran in the years 1960 and 1970 show that the number of crimes in the country had increased $68 \%$ in ten years, and this was despite the fact that in that period the income was on the rise unprecedentedly. Mr. Pynatl wrote in his "Criminal Law and Criminology": Since the beginning of the nineteenth century, a change in the economic situation of European countries emerged, in the sense that agricultural production was replaced by industrial production. This change resulted in higher levels of public life in the continent. But these changes have yielded an extra boost of criminals, so that, the f Financial Crime with respect to an increase in population and statistical correction increased 300\% compared to before." There is no doubt that wealth is causing offense in a way that poverty is not, so the Crime in affluent classes is not the same with the poor ones. If the greatest crimes in poor people are simple robbery and assault and battery, the fundamental crime of the rich class is what the 
Americans have called it white-collar crime. Mr. Stefani, in explaining the impact of crime creation of wealth and prosperity, says: "This period is not dangerous for public order less than the economic crisis, because of the development of modern luxury and production requirements and because all social classes are not benefited evenly from the economic spread and the meet of luxury sense and new requirements for all people is not possible from legal ways; inevitably groups, particularly young people resort to illegitimate means" (Kei Nia, 1991: 197).

This explanation is what has been emphasized by many scholars. The third United Nations Congress on Crime Prevention and treatment of criminals, which was consisted of thousands of judges, law professors, sociologists, and police officers in 1965 in Stockholm, after a week of work declared: "a great affinity for more spending, is the origin and the cause of many crimes that occur around the world." Studies Committee of violence and criminality that we talked about earlier, found the most important factors causing violence that the following factors are among them:

- Encouraging the consumption action and "consumerism" and undermining the social relations associated with the consumption.

- The sharp increase in the need for equality among citizens. This factor plays an important role in violence in companies and institutions operating in the development of services and manufacturing.

On the other hand the expansion of economic activities, makes the education and the full financing through illegitimate means possible. The prevalence of crimes such as speculation, issuing checks, fraud and white collar crime can be attributed to the period of economic growth. Increased individual and collective wealth is limitless in some countries, but criminal situation in these countries is rising steeply. The negative impact of accumulated wealth is derived from religious texts, too. God says in the first revelation to the Prophet PBUH about the result of needless flooding: Man feeling no need, outbursts even against his Lord. The verse says about the human nature, that if they have no need will be diverted from the right path. It has been narrated from Imam Ali (PBUH) that: "Multiplicity of property causes to heart corruption and forgetting sins." He also considered the increasing wealth as the source of destruction, rebellion and ruin. 
It has been narrated that the Prophet PBUH prayed in this way: O Allah! Grant To Muhammad and his lovers chastity and wealth as much as needed, and benefit his enemies of wealth and children.

The analysis of research hypotheses

First hypothesis: It seems that there is a relationship between the family income, annual spending power and committing theft.

Table 1. Correlation between household income and crime

\begin{tabular}{|c|c|c|c|}
\hline Variables & $\begin{array}{c}\text { Pearson correlation } \\
\text { coefficient }\end{array}$ & Significance level & $\begin{array}{c}\text { number of } \\
\text { samples }\end{array}$ \\
\hline $\begin{array}{c}\text { Family income. } \\
\text { Crime }\end{array}$ & 0.9 & 0.006 & 108 \\
\hline
\end{tabular}

As can be seen in Table 1 correlation between family income and crime with a correlation coefficient of 0.9 and 0.006 Significance level is achieved. Thus, according to the Significance level, the first hypothesis is confirmed and there is a positive correlation between the two variables.

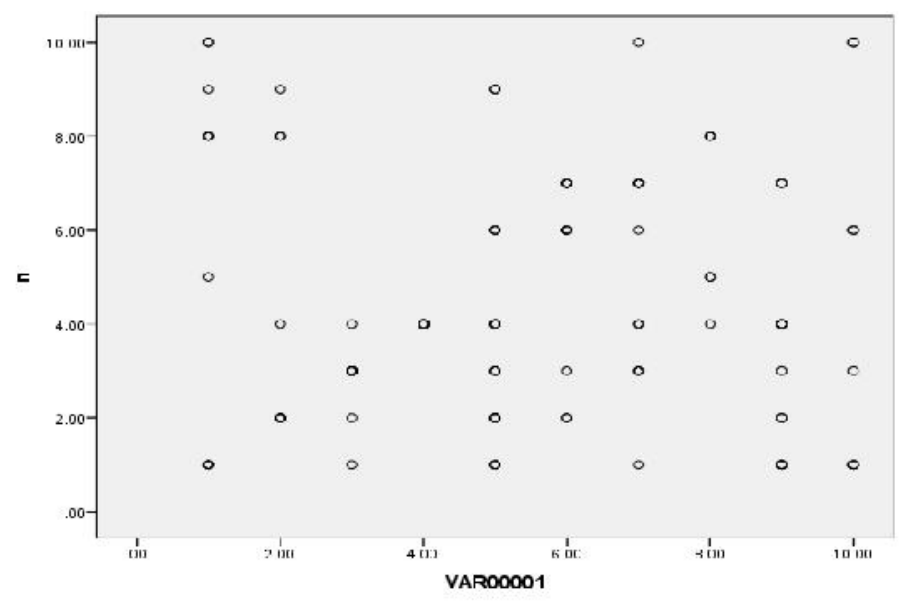

Fig.1. Correlation between household income and crime

Second hypothesis: It seems that there is a relationship between unemployment, drug addiction, a derelict or single-parent family, a lack of skills, and education and crime of theft.

1.2.3.4 It seems that there is a relationship between unemployment and crime. 
Table. 2. Correlation between unemployment and crime

\begin{tabular}{|c|c|c|c|}
\hline Variables & $\begin{array}{c}\text { Pearson correlation } \\
\text { coefficient }\end{array}$ & Significance level & number of samples \\
\hline $\begin{array}{c}\text { Unemployment. } \\
\text { Crime }\end{array}$ & 0.83 & 0.000 & 108 \\
\hline
\end{tabular}

Table 2 shows the results of two variables unemployment and crime in terms of their correlation. As it was shown, the correlation coefficient between the two variables is 0.83 and their significance level is 0.000 . Given the significant level, the correlation between two variables is confirmed, and a positive correlation was observed between the two variables.

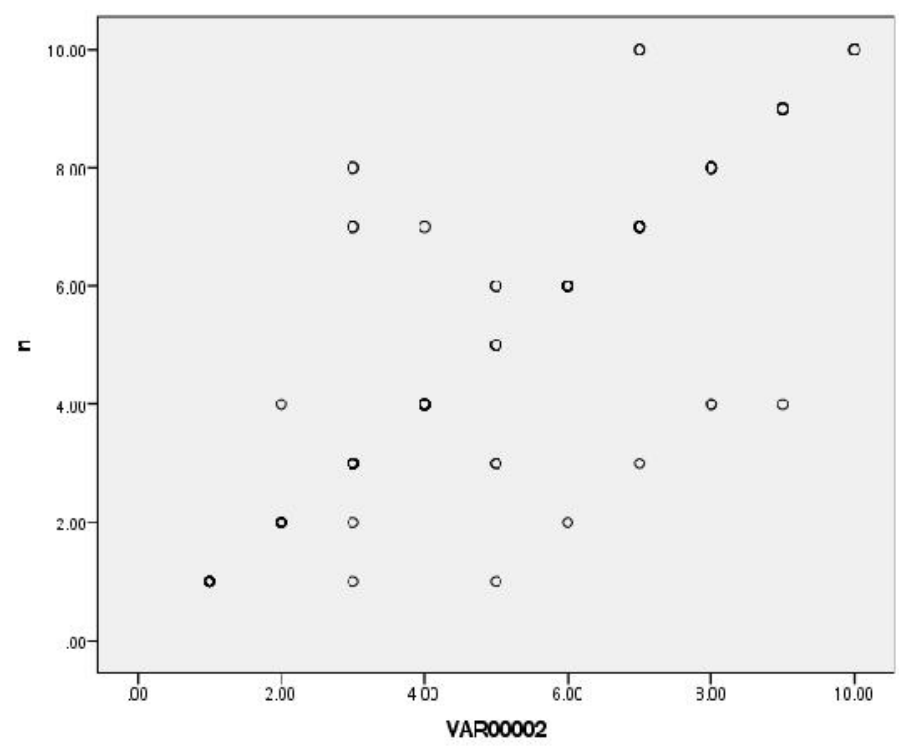

Fig. 2. Correlation between unemployment and crime

4.3.2.2 It seems that there is a relationship between supervision and crime.

Table 3. Correlation between supervision and crime

\begin{tabular}{|c|c|c|c|}
\hline Variables & $\begin{array}{c}\text { Pearson correlation } \\
\text { coefficient }\end{array}$ & Significance level & number of samples \\
\hline $\begin{array}{c}\text { Supervision status. } \\
\text { Crime }\end{array}$ & 0.50 & 0.06 & 108 \\
\hline
\end{tabular}


As can be seen in Table 3 correlations coefficients between supervision and crime were evaluated. Pearson correlation coefficient between the two variables is 0.50 and a significance level of 0.06 was obtained. Therefore, due to the significance level achieved, between the two variables has not been observed a strong and significant relationship, so the correlation between the two variables is rejected.

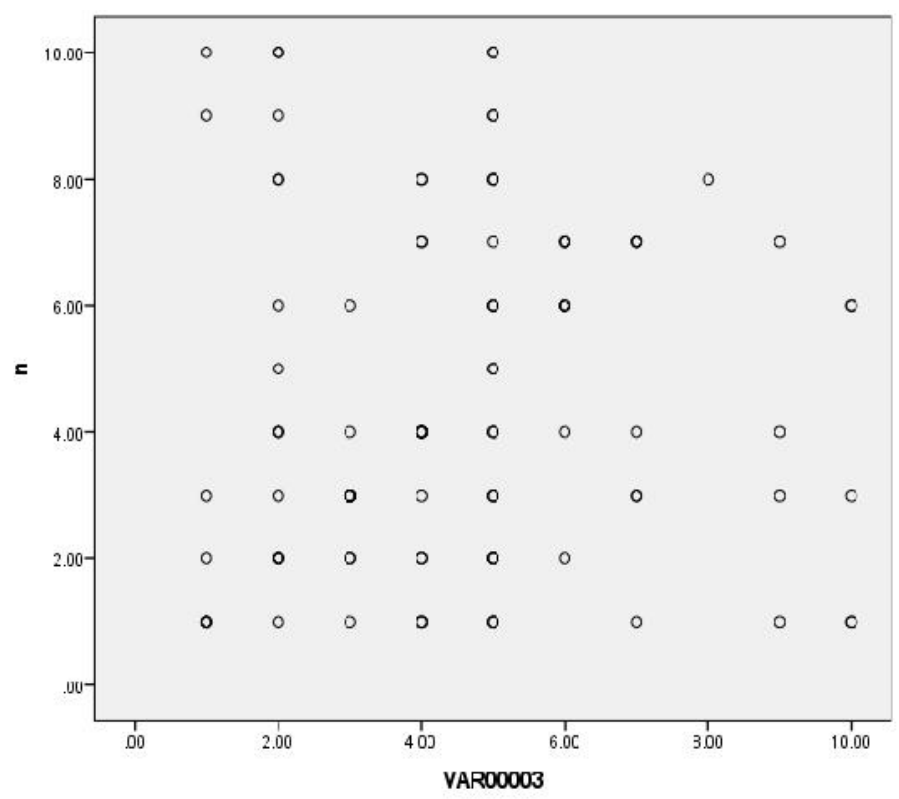

Fig.3. Correlation between supervision and crime

It seems that there is a relationship between addiction and crime.

Table 4. Correlation between addiction and crime

\begin{tabular}{|c|c|c|c|}
\hline Variables & $\begin{array}{c}\text { Pearson correlation } \\
\text { coefficient }\end{array}$ & Significance level & number of samples \\
\hline Addiction. Crime & 0.230 & 0.017 & 108 \\
\hline
\end{tabular}

The results of Table 4 shows the relationship between the two variables is positive and significant. The correlation coefficient between addiction and crime is 0.230 and the significance level is 0.017 . So the relationship between the two variables is confirmed. 


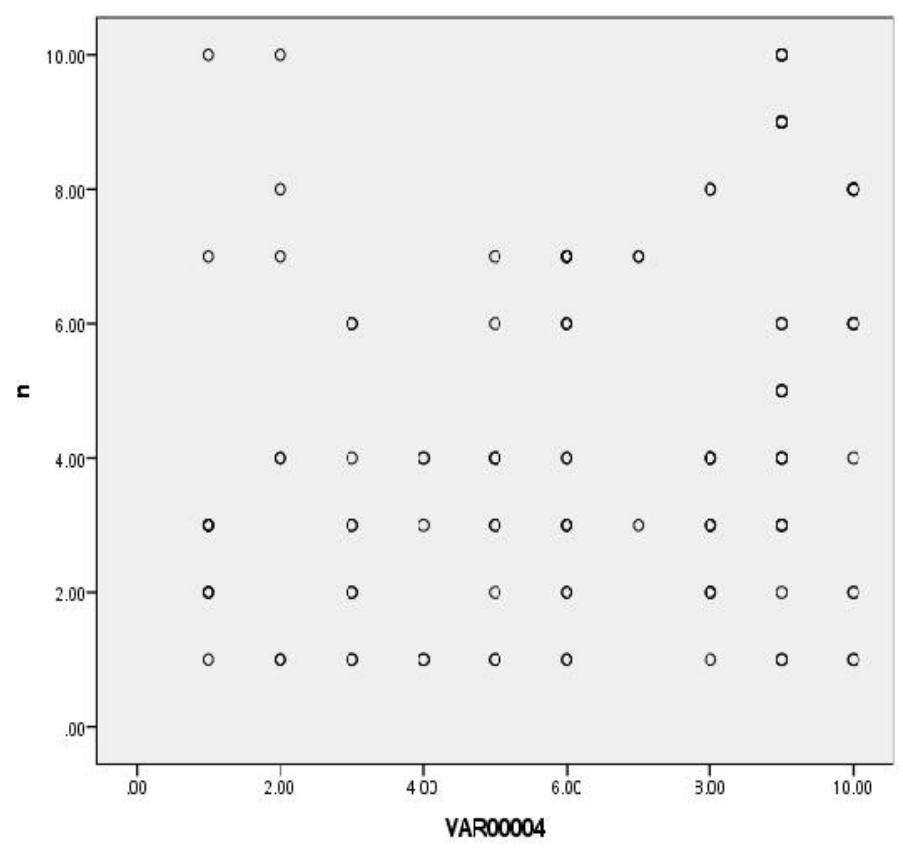

Fig.4. Correlation between addiction and crime

It seems that there is a relationship between lack of skills and crime.

Table 5. Correlation between lack of skills and crime

\begin{tabular}{|c|c|c|c|}
\hline Variables & $\begin{array}{c}\text { Pearson correlation } \\
\text { coefficient }\end{array}$ & Significance level & number of samples \\
\hline $\begin{array}{c}\text { Skills shortages. } \\
\text { Crime }\end{array}$ & 0.626 & 0.047 & 108 \\
\hline
\end{tabular}

The results of Table 5 shows the relationship between two variables of lack of skills and crime. Correlation between the two variables is 0.626 and significance level is 0.047 . Thus, according to the significance level the relation between two variables is relatively strong and positive. Therefore, this association is confirmed. 


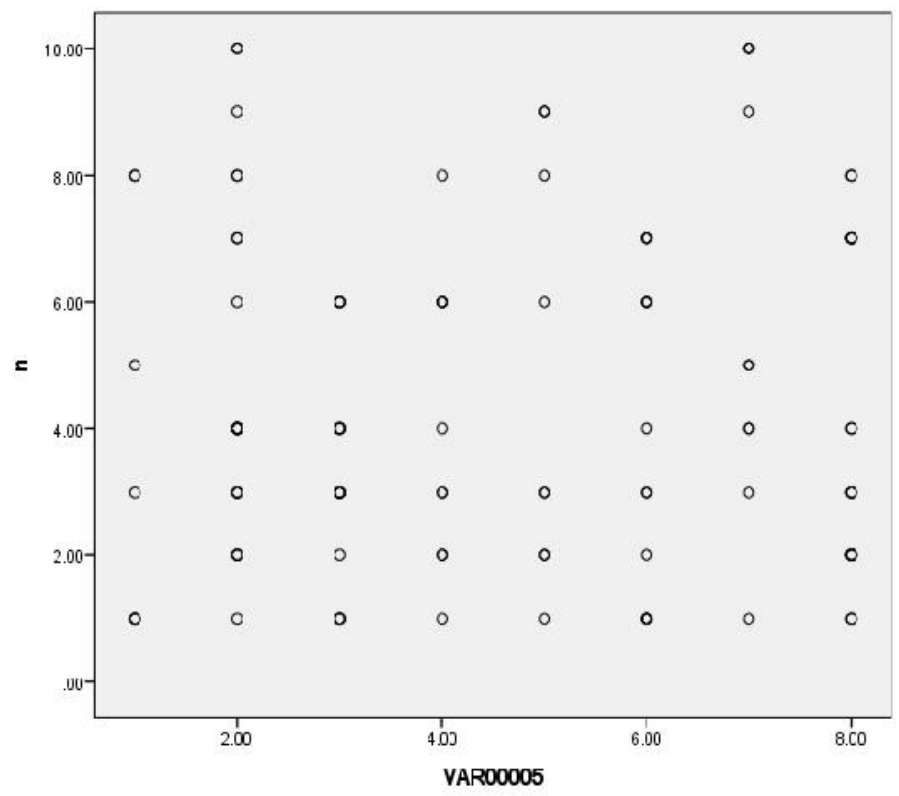

Fig.5. Correlation between lack of skills and crime

It seems that there is a relationship between education and crime.

Table 6. Correlation between education and crime

\begin{tabular}{|c|c|c|c|}
\hline Variables & $\begin{array}{c}\text { Pearson correlation } \\
\text { coefficient }\end{array}$ & Significance level & number of samples \\
\hline Education. Crime & 0.305 & 0.001 & 108 \\
\hline
\end{tabular}

The results of Table 6 illustrates the relationship between the two variables of education and crime. 0.305 correlation coefficient between the two variables and a significance level of 0.001 are obtained. Therefore, due to the significant level obtained in the above table, the relationship is relatively strong and a significant correlation between two variables. So it is approved. 


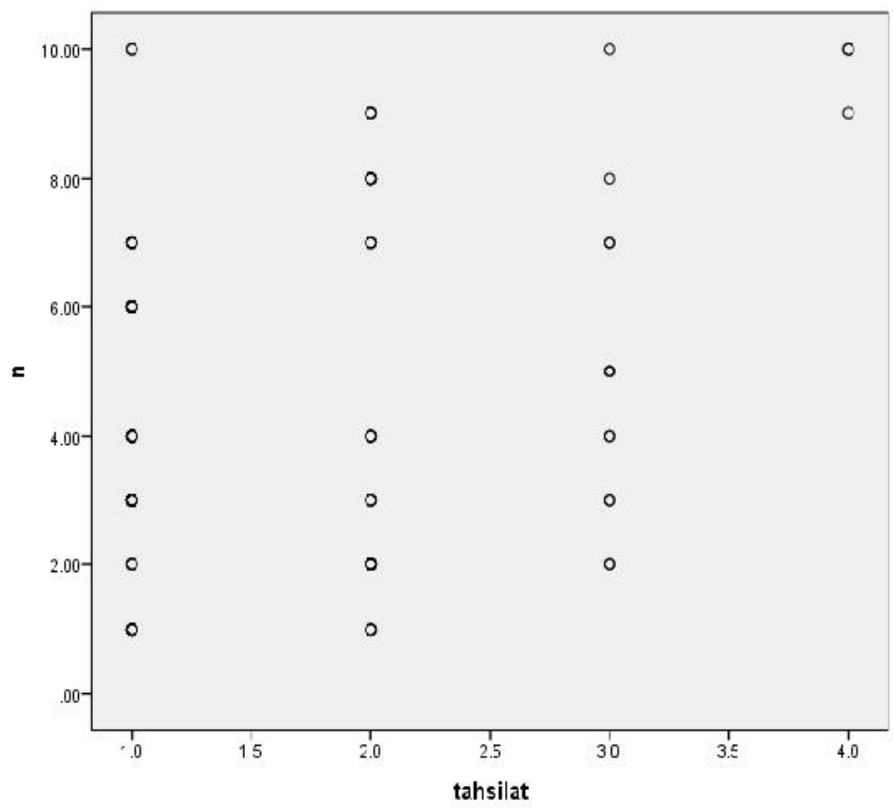

Fig.6. Correlation between education and crime

\section{4-4 Conceptual model:}

Factors affecting the crime of theft

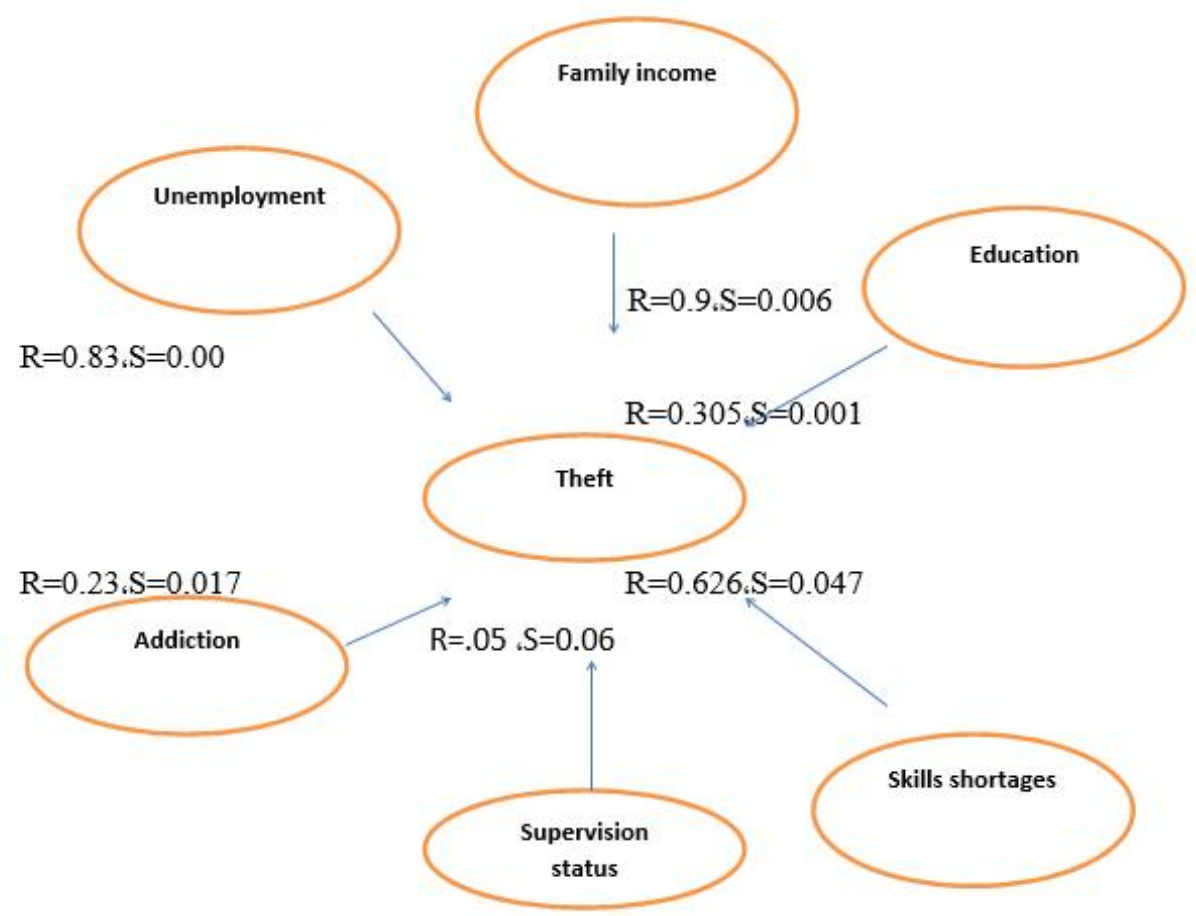

(The relationship between supervision and theft is rejected) 


\section{CONCLUSION}

Theft is one of the oldest human crimes, which has long been in different countries. Although this phenomenon over time has changed, but it remains stable and intact nature as condemned. However, with the passage of time and advancement of technology, methods of committing this offense and the type of property and stolen objects changed. Thieves nowadays use the latest techniques for achieving success. Accordingly the methods of coping with it have become more difficult. Achieve to the financial security of citizens requires the careful consideration and coordinate between the agencies and entities in charge of security, and to seek solutions and prevention of crime before treatment. Given that the most important parameters involved in the crime of theft is the economic factor, so we decided to check that and other influencing factors in the commission of this crime. The present study, entitled the role of home economics in the crime of theft, has been done among inmates, in Chaharmahal and Bakhtiari Province. The study population included all patients committed robbery in Shahr-e-kord prison $(n=108)$. (According to Morgan table, from 150 volunteers, 108 subjects, randomly selected by convenience sampling and were examined.) The statistical consisted of persons under 18 years of age, with a prevalence of 30.6 percent, the second group of $18-28$ year 37\%, the third group of $29-39$ years $21.3 \%$, and the fourth group of people 40 years and older $11.1 \%$, were observed. In terms of marital status it included married people with an abundance of 30.6 percent, the second group of single people with an abundance of 50.9 percent, the third group people divorced $16.7 \%$, and the fourth group of people who have lost their spouse are observed with a frequency of $1.9 \%$. The population in terms of education was consisted of people with education under high school education with a frequency of 53.7 percent, the individuals with high school diploma with a frequency of 31.5 percent, individuals with a bachelor's degree with a frequency of $12 \%$, and the fourth group of individuals with MA and higher levels $2.8 \%$. The study also analyzed two general assumptions by Pearson correlation. The first hypothesis: It seems that there is a relationship between the family income, annual spending power and committing theft. Correlation coefficient is 0.9 and the significance level is 0.006. Therefore, due to the significant level achieved, the first hypothesis is confirmed. This research is in line with the Hosseinnejad's research (2006). The second hypothesis: It seems that there are relationships between unemployment, drug addiction, and derelict or single-parent family, a lack of skills and education and crime of theft. The second hypothesis was separated into several parts and each part was analyzed separately. In 
Unemployment rate analysis, correlation coefficient of 0.83 and a significance level of 0.000 are obtained. So the relationship between the two variables is confirmed. This research is in line with researches of Sadeghi (2003) and Mashyr (2000). In the variable supervision status, with a correlation coefficient of 0.50 and a significance level of 0.06 , a strong and significant relationship between the two variables was not observed. Addiction variable, with a correlation coefficient of 0.230 and a significance level of 0.017 was approved. Variable skill deficiencies and weaknesses, with a correlation coefficient of 0.626 and a significance level of 0.047 was approved. This research is in line with the research of Witt (1998). In Education variable, with a correlation coefficient of 0.305 and 0.001 significance level, it was observed a strong and significant relationship between variables.

\section{REFERENCES}

1. Dehghan, Hamid (2001) The law of theft, Qom, the center of Islamic Publications Bureau

2. Sotoudeh, Hidayatullah (2003) social pathology (sociology of deviance). Tehran, publisher of The Sound of Light

3. Kay Nia, Mehdi (1991): Foundations of Criminology, Tehran University Press, vol. 2,

4. Gould, Julius; Kolb, William L. (1997): "Culture Social Sciences", Maziar, Tehran,

5. Mir Mohammad Sadeghi, H. (2014) Crimes against property and ownership, Tehran, publication of printed fortieth, Sixth Edition

6. Hamed et al., 2010, the economic, social and security causes of theft in Kermanshah

7. Sadiq. Rahmatullah (1997) analysis of theories of social deviance, College of Education, Journal of Faculty of Education, the eleventh year 1 and 2, Tehran: Tehran University.

8. GHIASI Hafezi, M. (2003), The views about the causes of the tendency of some Sirjan people to drugs, unpublished master's project, Kerman, education and research management, 2003.

9. Mohseni, Morteza (1999); social and economic foundations and its relationship with delinquency, taken from the site www.gtalk.ir.

10. Hatefi ARDAKANI, H. (2005), Characteristics of theft of places in Yazd, Khorramabad and eastern Tehran, comparative, social pathologies in Iran in the Proceedings of the National Conference, Volume 6, Tehran, Agah. 
How to cite this article:

Husseini M, Yaminpour V. The role of the family economy in theft in chaharmahal and bakhtiari province (case study of adult criminals in prison). J. Fundam. Appl. Sci., 2016, 9(1S), 276-290. 